\title{
FACTORES DE RIESGO EN MUJ ERES CON INFECCIÓN DEL VIRUS PAPILOMA HUMANO
}

\author{
Gustavo Oviedo 1, Ana Luisa Arpaia 2,a, Euclides Ratia 3, Nereida Seco 3, Iris \\ Rodríguez ${ }^{3}$, Zenair Ramírez ${ }^{3}$ \\ ${ }^{1}$ Departamento de Salud Pública, ${ }^{2}$ Departamento de Ciencias de la Conducta, Universidad de Carabobo, Venezuela. \\ ${ }^{3}$ Hospital Dr. Adolfo Prince Lara, Puerto Cabello, Venezuela.
}

a Licenciada en Educación.

\section{RESUMEN}

La infección por el Virus Papiloma Humano (VPH) es una enfermedad de transmisión sexual, que afecta a un elevado porcentaje de mujeres que viven en los países subdesarrollados. Objetivos: Identificar los factores de riesgo en mujeres con diagnóstico de VPH, habitantes de la ciudad de Puerto Cabello, Venezuela. Métodos: Investigación descriptiva, no experimental, en una muestra de 50 mujeres, con diagnóstico de VPH, con edades comprendidas entre 15-45 años. Resultados: El grupo mas afectado tenía entre 15-20 años de edad (44\%), seguido por el grupo entre $21-25$ años (30\%). El 70\% de las pacientes tuvo más de una pareja y el $96 \%$ tuvo su primera relación sexual antes de los 20 años; $18 \%$ eran fumadoras. Conclusiones: El VPH afecta principalmente a las mujeres con edad menor a 25 años, entre los factores de riesgo de mayor importancia se encuentra la edad de la primera relación sexual y el número de parejas sexuales.

\section{PALABRAS CLAVES: Papilomavirus humano, VPH, mujeres, relación sexual}

\section{SUMMARY}

The human papilomavirus infection (HPV) is a disease of sexual transmission, it affect an elevated percentage of women that live in underdevelopment countries. Objective: To identify the risk factors in women with HPV diagnostic, that living in Puerto Cabello City, Venezuela. Method: Descriptive and not experimental investigation, in a sample of 50 women, with HPV diagnostic, aged between 15-45 years old. Results: The more affected group had 15-20 years old (44\%), after the group between 21-25 years old $(30 \%)$. The $70 \%$ of patients had more of one pair and $96 \%$ had her first sexual relationship before 20 years old; $18 \%$ were smokers. Conclusions: The HPV affected principally the women with age before 25 years old, between the risk factors of more importance are the age of first sexual relationship and the pair number.

\section{KEY WORDS: Human papilomavirus, HPV, women, sexual relationship}

\section{INTRODUCCIÓN}

La infección por el Virus Papiloma Humano (VPH) constituye en nuestros tiempos una de las principales enfermedades de transmisión sexual, su prevalencia puede alcanzar hasta un
60 por ciento en las personas sexualmente activas (1). De las mujeres infectadas sólo 10 a 20 por ciento tienen lesiones clínicamente evidentes, las restantes requieren citología y biopsia dirigida por colposcopia para su diagnóstico $(2,3)$. 
Desde el punto de vista epidemiológico se comporta como una enfermedad de transmisión sexual. Dentro de los factores de riesgo descritos esta la edad temprana de inicio de las relaciones sexuales (antes de los 20 años), especialmente si se realiza durante el primer año tras la menarquia. Así mismo debe considerarse la promiscuidad, ya que si la persona tiene varios compañeros sexuales en un corto período de tiempo, mayor será la exposición al VPH, de tal manera que el comportamiento sexual incrementa el riesgo de padecer dicha enfermedad $(1,4,5,6)$. El hábito de fumar parece ser estadísticamente otro factor de riesgo para el VPH. En Venezuela, se ha observado que la edad promedio para el diagnóstico de VPH es de 25 años y la mayor incidencia de la enfermedad es alrededor de los 20 años, no obstante en los últimos años ha aumentado su diagnóstico en edades más tempranas (7). En el Estado Carabobo para el año 2001, la incidencia de VPH alcanzó a 1203 casos, con una tasa de $56,2 /$ cien mil habitantes (8).

El objetivo de este estudio es identificar los factores de riesgo en la infección por VPH en mujeres que asisten al Servicio de GinecoObstetricia del Hospital "Dr. Adolfo Prince Lara" de Puerto Cabello, Venezuela, durante 2003.

\section{PACIENTES Y MÉTODOS}

Estudio descriptivo, no experimental y transversal, en donde se miden las características de las personas en estudio, las variables no son controladas por los investigadores y se recolectan los datos en un solo momento de la investigación (9).

La población estuvo representada por las pacientes consultantes en el Servicio de GinecoObstetricia del Hospital "Dr. Adolfo Prince Lara" de Puerto Cabello, durante el período enero de 2003 a enero de 2004. Se estudiaron 50 pacientes quienes presentaban diagnóstico de VPH, de las cuales 46 pacientes tenían diagnóstico por clínica y 4 presentaban diagnóstico por estudio citológico.

Se tomaron en cuenta las variables edad, antecedentes gineco-obstétricos de las pacientes (edad de la primera relación sexual y número de parejas sexuales), así como la presencia de hábito tabáquico.

Se presentan los resultados en tablas, expresados en frecuencias absolutas y relativas. La información fue suministrada por el Departamento de Historias Médicas del Hospital "Dr. Adolfo Prince Lara".

\section{RESULTADOS}

En la Tabla I se observa la distribución de los casos según la edad de las pacientes con diagnóstico de $\mathrm{VPH}$, encontrando que el grupo entre 15 y 20 años de edad representan un $44 \%$, seguido por el grupo de 21 a 25 años con un $30 \%$, mientras que en las mujeres con edades mayores a 35 años la incidencia fue de $8 \%$.

En la Tabla II se analiza la distribución de los casos según el número de parejas de cada paciente, encontrando que 21 de las pacientes (42\%) habían tenido 2 parejas; seguido de 15 pacientes $(30 \%)$ con una sola pareja, luego las pacientes que tuvieron 3 parejas (26\%) y una sola paciente con 4 parejas (2\%). Resultando que 35 de las mujeres estudiadas tuvieron más de una pareja, lo cual representa el $70 \%$.

En la Tabla III se observa la distribución de los casos según la edad de la primera relación sexual, encontrando que el $32 \%$ de las pacientes la tuvieron a los 15 y 16 años de edad, seguido de un $30 \%$ entre las que tenían 17 y 18 años. Se destaca que el $96 \%$ de las mujeres estudiadas tuvieron su primera relación antes de los 20 años.

Tabla I

DISTRIBUCIÓN DE LOS CASOS DE VPH SEGÚN LA EDAD DE LAS PACIENTES.

\begin{tabular}{lrr}
\hline Edad (años) & $n$ & $\%$ \\
\hline $15-20$ & 22 & 44 \\
$21-25$ & 15 & 30 \\
$26-30$ & 5 & 10 \\
$31-35$ & 4 & 8 \\
$36-40$ & 2 & 4 \\
$41-45$ & 2 & 4 \\
\hline Total & 50 & 100 \\
\hline
\end{tabular}

Tabla II

DISTRIBUCIÓN DE LOS CASOS DE VPH SEGÚN EL NÚMERO DE PAREJAS.

\begin{tabular}{lrr}
\hline Parejas sexuales & $n$ & $\%$ \\
\hline 1 & 15 & 30 \\
2 & 21 & 42 \\
3 & 13 & 26 \\
4 & 1 & 2 \\
\hline Total & 50 & 100 \\
\hline
\end{tabular}


Tabla III

\section{DISTRIBUCIÓN DE LOS CASOS DE VPH SEGÚN EDAD DE LA PRIMERA RELACIÓN SEXUAL.}

\begin{tabular}{lrr}
\hline Edad (años) & $n$ & $\%$ \\
\hline $11-12$ & 3 & 6 \\
$13-14$ & 7 & 14 \\
$15-16$ & 16 & 32 \\
$17-18$ & 15 & 30 \\
$19-20$ & 7 & 14 \\
$21-22$ & 0 & 0 \\
$23-24$ & 2 & 4 \\
\hline Total & 50 & 100 \\
\hline
\end{tabular}

En la Tabla IV se observa la distribución de los casos según hábito tabáquico, encontrando que solo 9 de las pacientes (18\%) fumaban cigarrillos; mientras que el $82 \%$, no tenían este hábito.

\section{DISCUSIÓN}

De acuerdo a estos resultados puede señalarse que el VPH afecta principalmente a las mujeres con edades menores a 25 años, alcanzando hasta un $74 \%$ de los casos estudiados; disminuyendo su incidencia a mayor edad. Este hallazgo pudiera explicarse por el hecho de que en estas edades hay mayor actividad sexual y promiscuidad. Lo cual reafirma lo señalado en el trabajo de investigación realizado por el Consejo de Desarrollo Científico y Humanístico de la Universidad de Carabobo, donde se encontró que el $58 \%$ de las mujeres portadoras del VPH tiene menos de 35 años, evidenciando que el virus está presente sobre todo en mujeres jóvenes (10). Por su parte Wieland y cols refieren que el inicio precoz de la actividad sexual ha sido reconocido como un importante factor de riesgo en la infección por VPH (11).

En relación a promiscuidad nuestros resultados coinciden con lo reportado por Capote, quien refiere que las relaciones sexuales con varias parejas constituyen uno de los principales factores de riesgo para la infección por VPH (5). Así mismo Catanho y Díguez, reportan que aquellas mujeres con un solo compañero tienen menos riesgo de infección por VPH, mientras que las mujeres con más de un compañero sexual, presentan mayor riesgo a padecer esta enfermedad (12). Por su parte Wieland y cols encontraron la presencia de VPH, cervical o vulvar entre 17 a $21 \%$ de las mujeres con una pareja sexual y entre 69 a $83 \%$ en aquellas con 5 o más parejas (11).
Tabla IV

\section{DISTRIBUCIÓN DE LOS CASOS DE VPH SEGÚN EL HÁBITO TABÁQUICO.}

\begin{tabular}{lrr}
\hline Hábito tabáquico & $n$ & $\%$ \\
\hline Ausente & 41 & 82 \\
Presentes & 9 & 18 \\
\hline Total & 50 & 100 \\
\hline
\end{tabular}

Capote sostiene que el comienzo de las relaciones sexuales a edades tempranas están presentes en el origen del VPH (5). En otros estudios igualmente se ha encontrado que la mayoría de las mujeres que tuvieron relación sexual antes de los 18 años presentaron mayor incidencia de VPH $(12,13)$, coincidiendo con los resultados obtenidos en este trabajo. Por otra parte hay que destacar que mientras mas temprano inicie la mujer las relaciones sexuales mayor son las probabilidades de tener varias parejas (10).

Aunque en esta investigación se encontró una bajo porcentaje de paciente fumadoras, en otros estudios se informa de una asociación positiva entre el hábito tabáquico e infección por VPH, ya que existen elevadas concentraciones de nicotina en el moco cervical y disminución de células de Langerhans en tejido cervical en pacientes fumadoras, lo cual favorecería la infección (3).

\section{CONCLUSIÓN}

En nuestra investigación el VPH afecta principalmente a las mujeres menores a 25 años y los factores de riesgo en orden de importancia fueron la edad de la primera relación sexual y el número de parejas.

\section{BIBLIOGRAFÍA}

1. Nazzal O, Reinero M, Abarzúa A, Liendo R, Palma C. Patología preinvasora del cervix. Rev Chil Obstet Ginecol 2003; 68(3): 189-196.

2. Lorincz R. Temas actuales del virus del papiloma humano. Vol. 4. México: Interamericana Mc GrawHill. 1996.

3. Medero S. Manual de enfermedad de transmisión sexual. Universidad de Los Andes, 1999.

4. Rivera R, Aguilera J, Larraín A. Epidemiologia del virus papiloma humano (HPV). Rev Chil Obstet Ginecol 2002; 67(6): 501-506.

5. Capote N. Ginecología del cáncer del cuello uterino. México: Interamericana Mc Graw-Hill; 1992. 
6. Sánchez M, Uribe F, Conde C. La infección por el virus del papiloma humano, un posible marcador biológico de comportamiento sexual en estudiantes universitarios. Sal Pub Mex 2002; 44: 442-447.

7. Ministerio de Salud y Desarrollo Social. División de Sistemas Estadísticas. Caracas, Venezuela; 2000.

8. INSALUD. Dirección de programas de salud. Causas de consultas del programa de SIDA/ITS. Estado de Carabobo, 1999-2001.

9. Hernández R, Baptista C. Metodología de la Investigación. Tercera Edición. México: Mc GrawHill Interamericana; 2003.

10. Consejo de Desarrollo Científico y Humanístico de la Universidad de Carabobo. Vírus de Papiloma Humano lo padecen en su mayoría las jóvenes.
Venpres [en línea] 2003. [fecha de acceso 25 de marzo de 2004]. Disponible en: http// www.venezuelainnovadora.gov.ve/noticias2003/ notisep20.html.

11. Wieland U, Pfister H. Papillomavirus in human pathology: Epidemiology, pathogenesis and oncogenic role. Chapter 1. In: Gross G, Barrasso R. Human Papilloma Virus Infection. Alemania: Editorial Ullstein Mosby 1997; 1-16.

12. Catanho C, Díguez A. Factores de riesgo en pacientes con diagnóstico de displasia de cuello uterino. Maternidad Concepción Palacios. Caracas; 1990.

13. Peña $F$, Moreno J. Manejo de las lesiones ginecológicas premalignas y malignas. Maternidad Concepción Palacios. Caracas; 1997. 